Pacific Journal of Mathematics

A NOTE ON THE CHARACTERIZATION OF CONDITIONAL 


\title{
A NOTE ON THE CHARACTERIZATION OF CONDITIONAL EXPECTATION OPERATORS
}

\author{
DANiel E. Wulbert
}

Let $(X, \Sigma, \mu)$ be an arbitrary measure space. A complete characterization is presented for the norm one positive projections $P$ of $L^{1}(X, \Sigma, \mu)$ into itself such that $\|f\|_{\infty} \geqq\|P f\|_{\infty}$ for each essentially bounded, summable function $f$.

If $(X, \Sigma, \mu)$ is a probability measure space it is known [1], [2], and [4] that such operators coincide precisely with the conditional expectation operators defined on $L^{1}$ (see definitions below). In this note we show that this characterization extends to an arbitrary measure space. The proof presented here is a direct, constructive proof requiring only basic measure theory. Although this extension is not unexpected, it does not seem to be a consequence of the methods used in the case for the finite measure spaces. An independent proof for this result, using the ergodic theory of Markov processes, was found by S. Foguel. Also extensions to arbitrary measure spaces of related theorems in [1], have recently been done by L. Tzafriri [5].

Definition. Let $\left(X, \sum, \mu\right)$ be a measure space. Let $\Sigma_{0}$ be a $\sigma$-subring of $\Sigma$. We call a projection $P$ on $L^{1}\left(X, \sum, \mu\right)$ a conditional expectation operator with respect to $\Sigma_{0}$ if $P f$ is $\Sigma_{0}$ measurable for all $f$, and if for each $U$ in $\Sigma_{0}$ we have

$$
\int_{U} P f d \mu=\int_{U} f d \mu .
$$

Clearly a conditional expectation operator is positive projection of norm one.

Notation. Let $P$ be a norm one positive projection from $L^{1}(X$, $\left.\sum, \mu\right)$ onto $E$. Let

$$
\Sigma_{0}=\{K \subseteq X: K=\operatorname{supp} f, f \geqq 0, f \text { in } E\} .
$$

We use supp $f$ to denote the support of a function $f$. The characteristic function of a set $A$ is written $1_{A}$.

LEMma $1 . \quad E$ is a lattice.

Proof. Let $f$ and $g$ be in $E$. Since $f \vee g$ dominates $f$ and $g$, $P(f \vee g)$ dominates $f, g$ and hence $f \vee g$. Since $\|f \vee g\| \geqq\|P(f \vee g)\|$, 
we have that $f \vee g=P(f \vee g)$.

Lemma 2. $\sum_{0}$ is a $\sigma$-ring.

Proof. We need to show that countable unions of members of $\Sigma_{0}$ are in $\Sigma_{0}$, and differences of members in $\Sigma_{0}$ are in $\sum_{0}$. Suppose $U_{i}$ is in $\Sigma_{0}$ for $i=1,2, \ldots$. Let $f_{i}$ be norm one positive functions in $E$ whose support in $U_{i}$. Then $f=\sum_{i=1}^{\infty}(1 / 2)^{i} f_{i}$ is a positive function in $E$ whose support is $\bigcup_{i=1}^{\infty} U_{i}$.

Suppose $U$ and $V$ are in $\Sigma_{0}$, and are the supports of positive fuction $f$ and $g$ in $E$.

Let

$$
f_{n}=(f-n g) \vee 0 \text {. }
$$

Let

$$
f^{\prime}(x)=\left\{\begin{array}{l}
f(x) \text { for } x \text { in } U-V \\
0 \text { otherwise }
\end{array}\right.
$$

From the dominated convergence theorem $f_{n}$ converges to $f^{\prime}$. Thus $U-V$ is in $\Sigma_{0}$

LEMMA 3. Suppose $f$ vanishes off some member of $\Sigma_{0}$. The following is true.

(i) $P(|f|)=0$ implies $f=0$.

(ii) if $K$ is in $\sum_{0}$ then $P\left(1_{K} f\right)=1_{K} P(f)$.

(iii) $\int_{K} P f d \mu=\int_{K} f d \mu$ for all $K$ in $\Sigma_{0}$.

Proof. We will assume that $f$ is nonnegative. Suppose $g$ is a nonnegative number of $E$ such that $f$ vanishes off supp $(g)$. Since $f \wedge n g$ increases monotonically to $f$, it suffices to assume that $f$ is bounded by a member of $E$. We will assume therefore that $0 \leqq f$ $\leqq g$. fore $f=0$.

(i ) $P(g-f)=g$ so $\|g\| \leqq\|g-f\|$, but $0 \leqq g-f \leqq g$. There-

(ii) Suppose that $h$ is a nonnegative member of $E$ such that supp $h=K$. Since $g \wedge n h$ converges monotonically to $1_{K} g$, it follows that $1_{K} g$ is in $K$.

Now $0 \leqq P\left(1_{K} f\right) \leqq P\left(1_{K} g\right)=1_{K} g$. Hence $P\left(1_{K} f\right)$ vanishes off $K$, and $P\left(1_{K} f\right) \leqq 1_{K} P(f)$. We also have $1_{K} g-P\left(1_{K} f\right)=P\left(1_{K}(\dot{g}-f)\right) \leqq$ $1_{K} P(g-f)=1_{K} g-1_{K} P(f)$. Thus $1_{K} P f=P\left(1_{K} f\right)$.

(iii) $\int_{K} f d \mu=\left\|1_{K} f\right\| \geqq\left\|P\left(1_{K} f\right)\right\|=\int_{K} P f d \mu$. Similarly 


$$
\begin{aligned}
& \int g d \mu-\int_{K} f d \mu=\int_{K}(g-f) d \mu=\left\|1_{K}(g-f)\right\| \\
\geqq & \left\|P\left(1_{K}(g-f)\right)\right\|=\int_{K}(P g-P f) d \mu .
\end{aligned}
$$

Hence $\int_{K} P f d \mu=\int_{K} f d \mu$.

For the remainder of the paper we will also assume that for each essentially bounded $f$ in $L^{1},\|f\|_{\infty} \geqq\|P f\|_{\infty}$.

Lemma 4. Each member of $E$ is $\sum_{0}$-measurable.

Proof. We first show that $g \wedge c$ is in $E$ for each constant function $c$ and each $g$ in $E$. It suffices to prove this assertion for positive functions $g$ and for $c>0$. However this is almost obvious for since $P$ is positive $g \geqq P(g \wedge c) \geqq 0$, and from the hypothesis $c \geqq P(g \wedge c)$. Thus $g \wedge c \geqq P(g \wedge c)$. Now with $K=\operatorname{supp} g$ Lemma 3 (iii) implies that $g \wedge c=P(g \wedge c)$.

It follows that for any $c, g-g \wedge c$ is in $E$. Hence if $g$ is a positive function in $E$, the set $\{x$ in $X: g(x)>c\}$ is also the support of $g-g \wedge c$, and thus is in $\Sigma_{0}$. Hence $P f$ is $\sum_{0}$ measurable for each $f$ in $L^{1}$.

Proposition. $P$ is the conditional expectation operator with respect to $\sum_{0}$.

Proof. Let $f$ be in $L^{1}$. Let $r=\sup \left\{\int_{K}|f| d \mu: K\right.$ in $\left.\sum_{0}\right\}$. Let $K$ be a member of $\sum_{0}$ such that $\int_{K}|f| d \mu=r$. Writing $f=1_{K} f+$ $\left(f-1_{K} f\right)$ we see that $f$ is the sum of a function which vanishes off a member of $\sum_{0}$ and a function which vanishes on each member of $\sum_{0}$. Thus in view of all the previous lemmas it remains only to show that $P f=0$ if $f$ vanishes on each member of $\sum_{0}$. We may assume that $f$ is bounded and nonnegative. Since the support of $n P f$ is in $\Sigma_{0}$, and since $f$ vanishes on all members of $\Sigma_{0}$, we have

$$
\|f+n P f\|_{\infty}=\max \left(\|f\|_{\infty}, n\|P f\|_{\infty}\right),
$$

but

$$
\|f+n P f\|_{\infty} \geqq\|P(f+n P f)\|_{\infty}=(n+1)\|P f\|_{\infty} .
$$

This implies that $\|P f\|_{\infty}=0$.

Remarks. The hypothesis that $\|f\|_{\infty} \geqq\|P f\|_{\infty}$ is equivalent to the assumption that $P\left(1_{A}\right) \leqq 1$ for all sets $A$ of finite measure. 
The referee has pointed out that the main result in this note is valied for norm one projections defined on $L_{p}$ spaces. Besides the proofs presented here, one would also use the fact that there do not exist two distinct norm one projections of a smooth space onto a subspace. (For $L_{p}$ spaces this result is in [1]. For smooth spaces a proof is in [6, Lemma 1]). The organization of this note was also suggested by the referee, and adapts to $L_{p}$ operators more readily than the original.

\section{REFERENCES}

1. T. Ando, Contractive projections in $L_{p}$ spaces, Pacific J. Math. 17 (1966), 391-405.

2. R.G. Douglas, Contractive projections on an $L_{1}$ space, Pacific J. Math. 15 (1965), 443-462.

3. Shu-Teh Chen. Moy, Characterizations of conditional expectation as a transformation of function spaces, Pacific J. Math. 4 (1954), 47-64.

4. G.L. Seever, Nonnegative projections on $C_{0}(X)$, Pacific J. Math. 17 (1966), 159-166.

5. L. Tzafriri, Remarks on contractive projections in $L_{p}$-spaces, Israel J. Math. (to appear)

6. D.E. Wulbert, Convergence of operators and Korovkin's theorem, J. Approximation theory, 1 (1968), 381-390.

Received February 18, 1969. This research was sponsored by National Science Foundation Grant No. GP-8175.

UNIVERSITY OF WASHINGTON

Seattle, Washington 


\section{PACIFIC JOURNAL OF MATHEMATICS}

EDITORS

H. SAMELSON

Stanford University

Stanford, California 94305

RichaRd PIERCE

University of Washington

Seattle, Washington 98105
J. DUGUNDJI

Department of Mathematics

University of Southern California

Los Angeles, California 90007

RICHARD ARENS

University of California

Los Angeles, California 90024

\section{ASSOCIATE EDITORS}

E. F. BECKENBACH

B. H. NeumanN

F. WOLF

K. YOSHIDA

\section{SUPPORTING INSTITUTIONS}

UNIVERSITY OF BRITISH COLUMBIA

CALIFORNIA INSTITUTE OF TECHNOLOGY

UNIVERSITY OF CALIFORNIA

MONTANA STATE UNIVERSITY

UNIVERSITY OF NEVADA

NEW MEXICO STATE UNIVERSITY

OREGON STATE UNIVERSITY

UNIVERSITY OF OREGON

OSAKA UNIVERSITY

UNIVERSITY OF SOUTHERN CALIFORNIA
STANFORD UNIVERSITY

UNIVERSITY OF TOKYO

UNIVERSITY OF UTAH

WASHINGTON STATE UNIVERSITY

UNIVERSITY OF WASHINGTON

AMERICAN MATHEMATICAL SOCIETY CHEVRON RESEARCH CORPORATION TRW SYSTEMS

NAVAL WEAPONS CENTER 


\section{Pacific Journal of Mathematics}

May, 1970

Johan Aarnes, Edward George Effros and Ole A. Nielsen, Locally compact

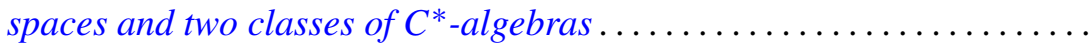

Allan C. Cochran, R. Keown and C. R. Williams, On a class of topological

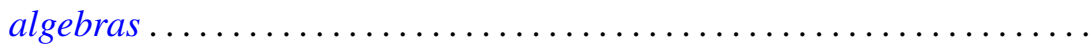

John Dauns, Integral domains that are not embeddable in division rings ....

Robert Jay Daverman, On the number of nonpiercing points in certain

crumpled cubes.....................................

Bryce L. Elkins, Characterization of separable ideals ................

Zbigniew Fiedorowicz, A comparison of two naturally arising uniformities

on a class of pseudo-PM spaces ...........................

Henry Charles Finlayson, Approximation of Wiener integrals of functionals

continuous in the uniform topology ........................

Theodore William Gamelin, Localization of the corona problem ...........

Alfred Gray and Paul Stephen Green, Sphere transitive structures and the

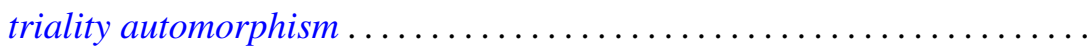

Charles Lemuel Hagopian, On generalized forms of aposyndesis ..........

J. Jakubík, On subgroups of a pseudo lattice ordered group ...............

Cornelius W. Onneweer, On uniform convergence for Walsh-Fourier

series..................................

Stanley Joel Osher, On certain Toeplitz operators in two variables ...

Washek (Vaclav) Frantisek Pfeffer and John Benson Wilbur, On the

measurability of Perron integrable functions............

Frank J. Polansky, On the conformal mapping of variable regions...

Kouei Sekigawa and Shûkichi Tanno, Sufficient conditions for a Riemannian manifold to be locally symmetric ...................

James Wilson Stepp, Locally compact Clifford semigroups ....

Ernest Lester Stitzinger, Frattini subalgebras of a class of solvable Lie

algebras ................................

George Szeto, The group character and split group algebras...

Mark Lawrence Teply, Homological dimension and splitting torsion

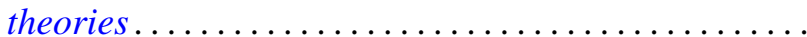

David Bertram Wales, Finite linear groups of degree seven. II ...

Robert Breckenridge Warfield, Jr., An isomorphic refinement theorem for

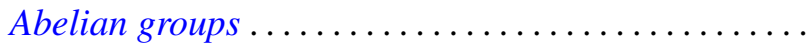

James Edward West, The ambient homeomorphy of an incomplete subspace

of infinite-dimensional Hilbert spaces................

Peter Wilker, Adjoint product and hom functors in general topology ...

Daniel Eliot Wulbert, A note on the characterization of conditional 